\title{
Dios visita a su pueblo en María"
}

\author{
Ana Francisca Vergara Abril** \\ Recibido: 31 de octubre de 2015 • Aprobado: 2 de diciembre de 2015
}

\section{Resumen}

María de Nazaret es, por excelencia, el arquetipo de creyente para todos los seguidores de Jesucristo. Ella es quien, gracias a su fiat, supo hacerse "toda oídos" para escuchar a Dios que la visitaba y la escogía para ser portadora del Mesías; al constituirse, al mismo tiempo, en portadora de la Buena Nueva para todas las generaciones. Es la mujer visitada por Dios y, desde esa experiencia, la que visita a otros y lleva a Dios mismo dentro de sí.

Palabras Clave: María, fiat, llamar, anunciación.

* Producto de la investigación de la autora. DOI: http://dx.doi.org/10.15332/s20119771.2016.0001.07

** Magister en Teología por la Pontifica Universidad Javeriana de Bogotá. Docente de la Facultad de Teología de la Universidad Santo Tomás. Correo electrónico: anafranciscavergara@ yahoo.co 


\title{
God visits his people in Mary
}

\begin{abstract}
Mary of Nazareth is, par excellence, the archetypical believer for all followers of Jesus Christ. She is the one who, through her fiat, gained to be "all ears" to listen to God who visited her and chose her to be the bearer of the Messiah; becoming, at the same time, the bearer of the Good News for all generations. She is the woman visited by God, and from that experience, the one who visits others and carries God himself within her.
\end{abstract}

Keywords: Mary, fiat, call, annunciation.

\section{Dieu visite son peuple en Marie}

\begin{abstract}
Marie de Nazareth est, par excellence, l'archétype du croyant pour tous les adeptes de Jésus- Christ. C'est elle qui, grâce à son fiat, a su devenir "toute ouïe" pour écouter Dieu qui la visitait et la choisissait pour être celle qui porterait le Messie; devenant, en même temps, la porteuse de la Bonne Nouvelle pour toutes les générations. C'est la femme visitée par Dieu et, à partir de cette expérience, celle qui visite les autres et porte Dieu en elle-même.

Mots-clés: Marie, fiat, appeler, annonciation.
\end{abstract}




\section{Dios sale al encuentro de su pueblo}

Iniciemos con el evangelio según san Lucas en el capítulo 1 versículos 26-38. Aquí nos encontramos con un texto maravilloso del que quizás aún no hemos logrado extraer todo el contenido. Es un pasaje rico en elementos que dejan ver a una María de Nazaret diferente. Veamos el texto:

${ }^{26}$ El sexto mes envió Dios al ángel Gabriel, a una ciudad de Galilea llamada Nazaret,

${ }^{27}$ a una virgen prometida a un hombre llamado José, de la familia de David; la virgen se llamaba María.

${ }^{28}$ Entró el ángel a donde ella y le dijo: Alégrate, llena de gracia, el Señor está contigo.

${ }^{29}$ Al oírlo, ella quedó desconcertada y se preguntaba qué clase de saludo era aquél.

${ }^{30}$ El ángel le dijo: No temas, María, que gozas del favor de Dios.

${ }^{31}$ Mira, concebirás y darás a luz un hijo, a quien llamarás Jesús.

32 Será grande, llevará el título de Hijo del Altísimo; el Señor Dios le dará el trono de David, su padre,

${ }^{33}$ para que reine sobre la Casa de Jacob por siempre y su reino no tenga fin.

${ }^{34}$ María respondió al ángel: ¿Cómo sucederá eso si no convivo con un hombre?

${ }^{35}$ El ángel respondió: El Espíritu Santo vendrá sobre ti y el poder del Altísimo te cubrirá con su sombra; por eso, el consagrado que nazca llevará el título de Hijo de Dios.

${ }^{36}$ Mira, también tu parienta Isabel ha concebido en su vejez, y la que se consideraba estéril está ya de seis meses.

${ }^{37}$ Pues nada es imposible para Dios.

${ }^{38}$ Respondió María: Yo soy la esclava del Señor, que se cumpla en mí tu palabra.

El ángel la dejó y se fue. (Lc 1, 26-38)

Quizás tengamos que cambiar un poco la imagen tradicional, particularmente católica, que poseemos de la Virgen María. Tenemos un concepto que hace de ella el arquetipo de la mujer sumisa en la Iglesia y en la sociedad. Muchas veces 
pensamos que parecernos a María es decir sí y obedecer aunque no se entienda nada, como si el fiat, que tanto amamos repetir, fuese un acto inconsciente. Puede ser que lleguemos a pensar que María, al acceder a la oferta del ángel Gabriel, se hubiera plegado a la voluntad divina para cambiar la imagen de la mujer rebelde introducida en el mundo por la acción de Eva, quien por definición es vista como la desobediente. Así, tantas veces, se considera que María al decir "sí" se ha olvidado de ella misma y de su propia responsabilidad.

Profesamos que María, por su maternidad virginal milagrosa, asumió su naturaleza femenina y se realizó totalmente como mujer en el momento en que dio a luz a Jesús. Pero, si vemos con detalle el pasaje evangélico, apreciándolo como una joya que recoge la historia de amor entre Dios y su pueblo, percibimos que en la época y en el contexto en que nació Jesús un "embarazo irregular" no hubiera sido posible: la mujer habría sido vista como adúltera, su hijo tildado de ilegítimo $\mathrm{y}$, puesto que se habría tratado de un embarazo por adulterio, ella debía haber sido lapidada. Es por esto que en el evangelio de Mateo la repudiación de José aparece en secreto (Mt 1, 19).

Es imposible imaginar semejante embarazo como Palabra de Dios, como buena noticia. ¿Una mujer prometida en matrimonio embarazada de otro? Con esta realidad, el evangelio ya nos pone en tensión y esto indica que no es un simple "cuento de hadas" en el que una adolescente se convierte en la madre de Dios.

¿Podemos pensar que María simplemente obedece porque sí? Esto no parece posible, pues la decisión de la joven madre muestra la determinación de una mujer con carácter, no de una niña. Una mujer que conociendo las leyes de su pueblo y de su religión está dispuesta a contradecirlas y a entrar en el grupo de los excluidos. Ella, la mujer, acepta valientemente entrar en una experiencia de fe a la que es convidada por el ángel.

La pareja acoge un hijo que, a todas luces, va a ser considerado como ilegitimo y, por lo mismo, rechazado. El ángel habla de un origen un poco dudoso. María, como judía, comprendía algo, pero no todo; sin embargo, ella es quien pone la última palabra: la joven doncella acepta y se apropia de su opción. La acogida y la confianza son constitutivos de María madre y creyente.

María da a luz un hijo como virgen. Virgen no en sentido fisiológico, sino en sentido de vida interior: pura, abierta, capaz de percibir y aceptar la voz del Señor Dios por medio de su mensajero. María, Virgen y Madre, es capaz de relacionarse con el otro al hacer que se respeten sus preguntas y al acoger la propuesta del Señor Dios. María engendra en ella a Jesús, más que en su cuerpo, en su alma virgen. Solo así ella puede ser modelo nuestro. 
María es la mujer que se pregunta y que cuestiona. El texto lo dice claramente. En el versículo 29 ella se pregunta: "Al oírlo, ella quedó desconcertada y se preguntaba qué clase de saludo era aquél."

Y, en el verso 34 ella pregunta: "María respondió al ángel: ¿Cómo sucederá eso si no convivo con un hombre?"

No todo se puede dar por hecho en nuestra relación con el Señor. Si bien es cierto que Dios visita a su pueblo y que se encarna en medio de él, como lo afirma el prólogo de Juan: "la Palabra se hizo carne y habitó entre nosotros" (Jn 1, 1), Dios no se impone. Es necesario la respuesta de la humanidad para acogerlo. María, quien representa al pueblo que Dios visita, da su aceptación voluntaria y responsable.

Detengámonos en cuatro datos importantes del texto de Lucas 1, 26-38:

- Al sexto mes,

- las cuatro veces que aparece el verbo llamar o llamarse,

- la concepción de María por la escucha

- y la presencia de la sombra que la cubre.

\section{a. Al sexto mes}

Este dato cronológico no es algo que el evangelista colocó en el texto porque le pareció agraciado que coincidiera con los seis meses de embarazo de Elizabeth. Al indagar un poco parece que bíblicamente hay algo más y de una gran profundidad.

El sexto mes reviste un valor y un significado. En la Primera Alianza (A. T.) esta frase aparece pocas veces. Particularmente hay dos textos reveladores en el Antiguo Testamento que hacen referencia a este momento: Ez 8, 1ss y Ageo 1,1 . Estos son pasajes que tienen que ver con el Templo y sobre todo con su reconstrucción.

Podemos afirmar que de un Testamento al otro hay un cambio de significación acerca del Templo: en el primero se hace referencia al Templo físico, a la construcción, al edificio, mientras que en el segundo es la persona misma que se convierte en Templo. Así lo expresa San Pablo claramente en 1Co 3, 16-17 mediante una pregunta:

¿No saben que son templo de Dios y que el Espíritu de Dios habita en ustedes?

Si alguien destruye el templo de Dios, Dios lo destruirá a él, porque el templo de Dios, que son ustedes, es sagrado (1Co 3, 16-17). 
Es decir, el Nuevo Templo del Señor son los creyentes. Se puede, de esta manera, aseverar que el Nuevo Testamento se abre y da paso a la realización de una promesa mesiánica: la reconstrucción del Nuevo Templo, en el que habitará el Mesías. De aquí resulta interesante subrayar que en la tradición católica llamemos a María Templo del Espíritu Santo.

\section{b. Las cuatro veces que aparece el verbo llamar}

En la información que el texto brinda se dice que la ciudad se llama Nazaret, que el prometido se llama José, que la Virgen se llama María y que el niño se llamará Jesús. Imposible no hacerse la pregunta: ¿Por qué tanto uso del verbo llamar?

El llamarse, que en hebreo se dice SheM tiene, como todo vocablo perteneciente a esta lengua, varias acepciones, también se puede traducir la palabra SheM por reputación, celebridad y monumento. Es decir que vamos más allá de la alusión de un simple deseo de poner nombre y somos invitados a descubrir, en cada uno de ellos, una vocación particular o una misión confiada:

- Nazaret significa al mismo tiempo: la escondida, el retoño, el consagrado.

- José, es el que aumenta, el que continúa.

- Myriam, la que se rebela.

- Jesús, el Señor salva.

Hay que reconocer nuestro nombre para saber a qué somos llamados. Cada uno de estos nombres se hace realidad en la vocación ejercida por la ciudad y por cada persona. Todos confluyen a hablarnos de la llegada del Mesías: de Nazaret vendrá el retoño de Jesé del que nos habla Isaías; gracias a la participación de José quien le aumenta el título de Hijo de David, el Mesías hijo de la que se rebela contra toda forma de esclavitud y que será el liberador de su pueblo y en él se hará realidad la salvación de Dios.

\section{c. María concibe por la escucha}

Muchos padres de la Iglesia repiten esta expresión: "María la Profetisa, a través del oído concibió al Dios viviente: pues el paso físico de las palabras es el oído" (Teodoro de Ancira). La relación palabra-oído-concepción, hunde sus raíces en antiquísimas civilizaciones. Por ello para los sabios antiguos, la vida entra en nosotros a través de los oídos.

Después de que el Ángel se dirige a la virgen y la saluda, y que la joven se pregunta sobre aquel saludo, el evangelista no vuelve a referirse a ella con 
el título de virgen, la llamará María y luego del nacimiento del Hijo la llamará madre de Jesús. Aquí se da el paso de la virgen a la madre y, como podemos observar, el oído es el medio.

\section{d. La clave del texto de la Anunciación: María es cubierta por la Shekiná}

Para concluir esta primera parte se quiere responder a un interrogante que se considera importante, al hacer eco de uno de los pasajes más hermosos del Antiguo Testamento. La pregunta es: ¿Qué hace que María responda positivamente y acepte la propuesta del ángel Gabriel?, o, dicho de otro modo, ¿Hay algo en las palabras del mensajero que haga reaccionar a la joven?

Se encuentra una clave profunda en el versículo 35:

El Espíritu Santo vendrá sobre ti y el poder del Altísimo te cubrirá con su sombra; por eso, el consagrado que nazca llevará el título de Hijo de Dios.

María, reconoce en el poder de la Sombra del Altísimo el mismo poder de la Shekiná, es decir de la presencia de Dios que acompañó a su pueblo en la travesía por el desierto. Así, el Nuevo Templo, la morada de Dios entre los hombres, será cobijada por la sombra de Dios. Este versículo es un eco del texto de Éxodo 40, 34-38 que dice:

Entonces la nube cubrió la tienda del encuentro, y la Gloria del Señor llenó el santuario. Moisés no pudo entrar en la tienda del encuentro, porque la nube se había apostado sobre ella y la Gloria del Señor llenaba el santuario.

En todas las etapas del camino cuando la nube se alzaba del santuario, los israelitas levantaban el campamento. Pero cuando la nube no se alzaba, los israelitas esperaban hasta que se alzase. Porque de día la nube del Señor se posaba sobre el santuario, y de noche el fuego brillaba en ella, a la vista de toda la casa de Israel. Y esto sucedía en todas las etapas del camino (Ex 40, 34-38).

terminemos este acercamiento al texto de la anunciación con las palabras de un monje de la iglesia ortodoxa: en la anunciación es donde "se ha realizado el misterio que sobrepasa todos los límites de la razón humana, la encarnación de dios" (monje gregorio; en: http://www.mariologia.org/fiesta/solemnidadesanunciacion40.htm; rrecuperado: 2 de septiembre de 2015). 


\section{Dios visita a su pueblo a través de María}

Entremos, en este segundo momento, en el texto que llamamos de la Visitación, Lc 1, 39-45. Es el pasaje que narra el encuentro de dos mujeres, dos madres, una más joven recién salida de su etapa de doncella y otra madura, ya en su etapa de ancianidad. Es el encuentro de dos vientres.

María sí que merece llamarse la entusiasta, la que lleva un Dios por dentro, que la mueve, la desinstala y la envía. Podríamos hablar del entusiasmo de dos vientres. Todo en este relato nos habla de llevar o sentir a alguien dentro.

María se pone en camino, va de Nazara a Ayn Karem, nombre dado por la tradición al pueblo de la región montañosa no lejos de Jerusalén, es decir del pueblo escondido al pozo de la vid, de un pueblo de Galilea, pequeño y sencillo, a un pueblo levítico, cercano a Jerusalén. Es un desplazamiento físico, espiritual y mental.

${ }^{39}$ En aquellos días, se levantó María y se fue apresuradamente a la región montañosa, a una ciudad de Judá; 40 entró en casa de Zacarías y saludó a Isabel.

${ }^{41}$ Y sucedió que, en cuanto oyó Isabel el saludo de María, saltó de gozo el niño en su vientre, e Isabel quedó llena de Espíritu Santo; ${ }^{42}$ y exclamando con gran voz, dijo: «Bendita tú entre las mujeres y bendito el fruto de tu vientre; ${ }^{43}$ y ¿de dónde a mí que la madre de mi Señor venga a mí? ${ }^{44}$ Porque, apenas llegó a mis oídos la voz de tu saludo, saltó de gozo el niño en mi vientre. ${ }^{45}$ ¡Feliz la que ha creído que se cumplirían las cosas que le fueron dichas de parte del Señor!» (Lc 1, 39-45)

Hermosamente el versículo 39 sitúa al lector en la dinámica del envío misionero y de la prontitud para salir hacia los otros.

Al tomar el pasaje de la Visitación nos detendremos en las siguientes ideas:

- El entusiasmo de María.

- María que entra en la casa de Zacarías y Elizabeth.

- $\quad$ El encuentro de dos vientres.

- Y los títulos marianos en boca de Elizabeth.

\section{a. El entusiasmo de María}

A todos nos gusta ver gente entusiasta, y a los otros les gusta vernos entusiasmados, pero ¿nos hemos detenido a reflexionar sobre el sentido del entusiasmo? 
El entusiasmo es la exaltación del ánimo que se produce por algo que cautiva o que provoca admiración. El término procede del latín tardío enthusiasmus, aunque su origen más remoto se encuentra en la lengua griega. En griego se dice enthousiasmos, una palabra formada de enthous, que significa que se lleva un dios por dentro. Para los griegos, entusiasmo significaba "tener un dios dentro de sí". La persona entusiasmada, por lo tanto, era aquella guiada por la fuerza y la sabiduría de un dios, capaz de hacer que ocurrieran cosas.

El Jasidismo, corriente judía, rechaza la melancolía, pues para este grupo este sentimiento es como un obstáculo que impide el encuentro entre el hombre y la divinidad. Dios es gustoso de ser reverenciado con regocijo y con canciones alegres. La alegría debe ser coronada por la hitlahavut, un entusiasmo inflamado, que permite que el alma se exalte con ardor por Dios, cuya presencia se encuentra por doquier.

Hitlahavut, según el pensamiento judío, vendría a ser el éxtasis, el fervor sin límites que por medio de la gracia atrapa al hombre para que éste responda al Creador de corazón, superando el espacio y el tiempo.

Así, María de Nazaret en su urgencia para ponerse en camino manifiesta que es habitada por el entusiasmo. Dios la mueve, la anima, de aquí que como lo dice claramente el texto esté pronta para ponerse en pie y desplazarse con rapidez. Sin duda que a la vez que se mueve ágilmente lo hace con la alegría de quien siente que cada una de sus acciones es motivada por Dios que la impulsa desde dentro.

\section{b. María entra en la casa de Zacarías y de Elizabeth}

Este hecho es importantísimo, no es a cualquier lugar a donde María se dirige, ni es cualquier casa que la recibe. Es la casa de Zakarias, y este nombre tiene un gran significado: Zakarias viene de ZaKoR: 'acordarse', del verbo ZeKeR, que significa: "memoria, recuerdo".

María se desplaza a Ayn Karem, no solo para asuntos domésticos, como solemos decir: para ayudar a su prima que va a dar a luz, ni tampoco para protegerse de las miradas de los curiosos de Nazaret. Ella se dirige al pueblo del Pozo de la Viña, y en particular a la Casa de la Memoria. Va allí para ser confirmada por Elizabeth, cuyo nombre significa Mi Dios es Plenitud, que representa junto con Zakarias, a los ancianos, a los sabios, quienes desde la Memoria Viva pueden corroborar su sí.

Todos necesitamos ser confirmados, en nuestra vocación. La confirmación viene de Dios a través de los otros. 


\section{c. El encuentro de dos vientres}

A Jesús solo se le puede portar en las entrañas, en el vientre. Así la misericordia de Dios y la misericordia de la humanidad, representada en la mujer, hacen que Jesús sea llevado a los otros.

Éste es uno de los textos de encuentro entre mujeres más bello de la Escritura; el vientre, ReHeM en hebreo y koilía en griego, es importante ya que las entrañas cuentan mucho. Es un símbolo delicado y fundamental, no solo porque es imagen de ternura y fecundidad, sino también porque es signo de la vida. Tanto hombres como mujeres poseemos un vientre, pero solo la mujer desarrolla en medio de sus entrañas, la matriz, la vida. Recordemos que la palabra misericordia en hebreo RaHaMYM, que también significa: ternura, compasión, piedad, gracia y bondad, viene de la palabra ReHeM: útero, matriz, vientre.

Así, el texto de la Segunda Alianza se abre, en Lucas con dos mujeres: Elizabeth y Myriam; con el encuentro de dos vientres cargados de vida. El encuentro de dos Alianzas, la Primera representada en la mujer estéril pero con su vientre cargado, imagen de Sara, Rebeca, Raquel y Ana, y la Segunda figurada en la joven virgen madre.

María y Elizabeth, dos vientres plenos: María llena de Jesús y Elizabeth llena del Espíritu Santo. Podríamos afirmar que Dios visita a su pueblo, a través de quienes prestan su vientre para acogerlo. Dios visita a su pueblo en los misericordiosos y son éstos quienes lo llevan a los otros.

\section{d. Los títulos marianos en boca de Elizabeth}

María recibe de Elizabeth, de Mi Dios es plenitud, tres títulos importantes:

La Bendita entre las mujeres: Barujá barujot, Elizabeth emplea la manera superlativa de los hebraísmos para decir que es lo máximo. Ella es la bendita por excelencia pues hay otras benditas que la Primera Alianza ha venido ofreciéndonos:

Yaél en Jueces 5, 24. Que significa la cabra salvaje.

Ruth en Rt 3, 10. Que significa Amiga.

Abigail en 1S 25, 33. Que significa la alegría del padre.

Sara la mujer de Tobías en Tb 11,17. Que significa princesa.

Judith en Judit 13,18;14,7, 15,10. Que significa la judía.

La mujer de los Proverbios en Pro 31, 28. 
La Dichosa, la Asheré, la mujer en camino de santidad, como traducen algunos sabios judíos esta palabra, María es la bienaventurada.

La Madre de mi Señor, la Madre de Dios, el título que cuatro siglos más tarde recibirá María en el Concilio de Éfeso como la Teotokos, ya está en boca de Elizabeth.

Las representaciones iconográficas más antiguas que escriben, como dicen los pintores de iconos, este episodio, que sólo cuenta Lucas, se remontan al siglo VI. En el icono las dos mujeres se abrazan. El pie de Elizabeth casi tropieza por la prisa. El encuentro de las dos mujeres transmite emoción. El paño rojo tendido entre los dos edificios indica que el encuentro se produce bajo la mirada misericordiosa del Señor.

Dos mujeres embarazadas que se encuentran y se abrazan. Desde siempre han sido el símbolo de la ayuda recíproca entre mujeres en el momento tópico femenino: el parto. Pero también de un momento fundamental en la historia de la Encarnación: es una mujer, la primera en reconocer en María a la madre del Mesías. Y a enseñarnos las palabras con que nos dirigimos a ella. Por eso la imagen de la Visitación desde hace siglos es el icono de la relación entre mujeres en la cultura cristiana: ayuda y reconocimiento recíproco son el mensaje que todavía hoy nos sugiere.

\section{Dios visita a su pueblo liberándolo}

El pasaje de la Visitación se prolonga con el Magníficat que continúa en la línea de otros cánticos del Antiguo Testamento y que manifiestan la acción liberadora de Dios.

\footnotetext{
${ }^{46}$ María dijo: Mi alma canta la grandeza del Señor,

${ }^{47}$ mi espíritu festeja a Dios mi salvador,

${ }^{48}$ porque se ha fijado en la humillación de su esclava y en adelante me felicita-

rán todas las generaciones.

${ }^{49}$ Porque el Poderoso ha hecho grandes cosas por mí, su nombre es santo.

${ }^{50} \mathrm{Su}$ misericordia con sus fieles se extiende de generación en generación.

${ }^{51}$ Despliega la fuerza de su brazo, dispersa a los soberbios en sus planes,

${ }^{52}$ derriba del trono a los poderosos y eleva a los humildes,
} 
${ }^{53}$ colma de bienes a los hambrientos y despide vacíos a los ricos.

${ }^{54}$ Socorre a Israel, su siervo, recordando la lealtad,

${ }_{55}^{5}$ prometida a nuestros antepasados, en favor de Abrahán y su descendencia para siempre $t$

Entre los cánticos de la Primera alianza el más conocido de ellos es el de Ana en 1Sam 2, 1-10, pero también poseemos otros Magnificats, himnos que engrandecen la acción de Dios: en Tob 13, en Dan 2, 20-23 e incluso podríamos referirnos al cántico de Nabucodonosor en el capítulo 4, 34 del libro de Daniel, muy cercano en sus palabras al de Lucas:

Y ahora yo, Nabucodonosor,

alabo y ensalzo y glorifico al Rey del cielo,

porque sus obras son justas y rectos sus caminos;

al que procede con soberbia lo humilla (Dan 4, 34 ).

Quisiera referirme a las dos Myriams o Marías, cada una de ellas perteneciente a una de las Alianzas. Myriam, hermana de Moisés y de Aarón en el Antiguo Testamento y María de Nazaret en el Nuevo. Las dos que representan al pueblo de Israel, son mujeres que expresan con su canto las maravillas del Señor. Además de todo lo que son, también son artistas.

Ex 15, 20-21 nos dice que Myriam tomó la vocería de las mujeres y las motivó a cantar, tocar y danzar su liberación una vez pasado el Mar Rojo.

${ }^{20}$ María, la profetisa, hermana de Aarón, tomó su pandereta en la mano, y todas las mujeres salieron con panderetas a danzar detrás de ella. 21María entonaba: "Canten al Señor, que se ha cubierto de gloria; caballos y carros ha arrojado en el mar" (Ex 15, 20-21).

De la misma manera Lucas nos presenta el canto de María. En ella todas las mujeres se unen, danzan y cantan la liberación de Israel y enaltecen la misericordia de Dios en favor de los más pequeños.

Entrando más en el texto de Lucas vemos que este cántico está formado por dos partes: en la primera, versículos 46 a 49, encontramos una acción de gracias muy de tipo personal. En ella María exulta frente a la acción maravillosa de Dios en su propia persona. De pequeña y humilde se siente agraciada. 
En la segunda parte, versículos 50 a 55, María asume la realidad de su pueblo y la manera como Dios lo ha visitado, por ello da gracias. El Dios al que María canta y alaba es el Señor que prefiere a los pobres, es el Misericordioso que acoge a los humildes y a quienes son ignorados por los ojos de los poderosos.

La gran constatación del pueblo de Israel es que Dios nunca los ha abandonado, que ha sido fiel a sus promesas desde el inicio, desde Abraham hasta hoy y que siempre toma partido por los débiles y desprotegidos.

El cántico de María pone en la balanza por un lado a los poderosos, soberbios, orgullosos y ricos y por el otro a los fieles, a los humildes, a los hambrientos y a los pobres. Por estos últimos el Señor se inclinará siempre. Este es el Dios que visita a su pueblo y María es la mediadora para que él se encarne. Una mujer judía plena de toda la tradición del pueblo de Israel, que conoce su historia y a través de ella la cercanía de Dios, y que permite que el Señor la visite, haciéndose portadora de él mismo en su seno y ofreciéndolo a la humanidad.

Concluyamos retomando las palabras del documento de Aparecida que nos presenta a María como Madre de la comunidad de creyentes en su hijo Jesús:

Como en la familia humana, la Iglesia-familia se genera en torno a una madre, quien confiere "alma" y ternura a la convivencia familiar (Cf. DP 295). María, Madre de la Iglesia, además de modelo y paradigma de humanidad, es artífice de comunión. Uno de los eventos fundamentales de la Iglesia es cuando el "si" brotó de María. Ella atrae multitudes a la comunión con Jesús y su Iglesia, como experimentamos a menudo en los santuarios marianos. Por eso la Iglesia, como la Virgen María, es madre. Esta visión mariana de la Iglesia es el mejor remedio para una Iglesia meramente funcional o burocrática. (D.A. 268)

\section{Referencias}

Biblia de Jerusalén. (2009). Bilbao: Desclée de Brouwer.

Documento de Aparecida. (2007). Bogotá: Celam.

MonjeGregorio.(s.f.);en:http://www.mariologia.org/fiesta/solemnidadesanunciacion 40.htm; recuperado: 2/09/2015). 